\title{
Artigo
}

\section{A IMPORTÂNCIA DA \\ A IMPORTÂNCIA DA
ESCRITA NA CLÍNICA DO AUTISMO}

vezes muito desenvolvida, ou tras vezes idiossincrática. Dessa forma, pode-se encontrar uma situação em que, contrariamente ao que se observa nas crianças de desenvolvimento dito padrão, é pela escrita e pela alfabetização Leda Mariza Fischer Bernardino que a criança considerada autista começa a ter possibilidades de comunicação com o outro. Se para Lacan a escrita é primeira em relação à fala, buscamos encontrar em conceitos como letra, significante e gozo um caminho de entendimento possivel desse universo autístico tão enigmático, que possa nos trazer subsidios para a direção de tratamento dessas crianças.

Descritores: autismo; escrita; pulsão; letra; significante; gozo.

Introdução

DOl: http//dx.doi.ors/10.11606/issn. 1981-1624.v20i3p504-519<smiles>c1ccccc1</smiles>

real da clínica nunca deixa de nos surpreender e de nos convocar ao exercício da escrita para tentar simbolizá-lo. Este trabalho ${ }^{1}$ foi provocado por um fato clínico: a criança com autismo, que não se comunica oralmente, que não estabelece uma interação com o outro como é usual nesse quadro clínico -, quando começa a ter acesso à escrita pode iniciar essa comunicação expressando-se por ela. Esse fato pode dar lugar a uma experiência inaugural de relação com o outro em que finalmente ela consegue transmitir algo para alguém através da linguagem. Isso pode mobilizá-la, inclusive, a querer se expressar oralmente.

- Psicanalista, doutora em Psicologia Clínica pela Universidade de São Paulo (USP). Analista membro da Associação Psicanalítica de Curitiba (APC) e pesquisadora do Laboratório de Estudos e Pesquisas Psicanalíticas e Educacionais sobre a Infância (LEPSI

IP/FE-USP), São Paulo, SP, Brasil.

504 Estilos clin., São Paulo, v. 20, n. 3, set./dez. 2015, 504-519. 
Isso pode parecer surpreendente, já que inverte a lógica com a qual estamos acostumados - de que uma criança primeiramente fala para depois escrever -, mas está de acordo com a afirmativa de Lacan (1995) de que "há uma primazia da escrita" (p. 155). Por isso o interesse em entender melhor essa escrita de que fala Lacan, a partir do conceito de "letra".

A partir dessa afirmativa lacaniana, pretende-se discutir este fato clínico para refletir sobre o papel da escrita na direção de tratamento da criança autista, tanto em consultório quanto em instituição.

Uma primeira observação que se pode fazer é que no autismo o encontro com o Outro primordial não se dá, no sentido de que a criança não estabelece um laço com esse agente encarregado de encarnar, para ela, a função de introduzi-la no campo da linguagem, da cultura e da sociedade. Em consequência do não estabelecimento desse laço, a criança recusa a interação com o outro, estabelece interações muito superficiais ou permanece indiferente a estas, o que pode acarretar uma ausência total de comunicação com o outro ou uma comunicação precária, mecânica, superficial, sem uma expressividade pessoal, uma "fala destacada do laço social" (Soler, 2010, p. 15), ou seja, fora do discurso.

Assim, no que se refere ao processo de constituição subjetiva, que introduz o filhote humano na linguagem e que falha para a criança com autismo, esta ficaria em uma situação peculiar, de não inscrição do significante, embora podendo, em alguns casos, usá-lo. Alguns autores chegam a citar que no autismo não há Outro, como Rosine e Robert Lefort (2003): "Não há Outro entendido como um lugar, não uma pessoa: lugar do significante, das palavras, do objeto, lugar da dialética da linguagem" (p. 8). Outros autores, como Vorcaro (2010) e Zuliani (2008), propõem que há Outro no autismo, mas essa função teria de ser qualificada em relação aos registros do Real, do Simbólico e do Imaginário (R, S, I), para definir de qual Outro se trata. Vorcaro (2010) questiona se poderia ser um "Outro Real duplicado" (p. 155), uma particular configuração de RSI no Outro no autismo, em que a criança considera o Outro (Simbólico) através da possibilidade de fazer dele espelho (Imaginário) com o Real de seu próprio corpo, duplicando-o.

Temos então uma criança que não fala, ou fala por ecolalia, através de um banco de palavras memorizadas, tomadas de um semelhante, outro, ou diretamente do Outro representado pelo dicionário, por exemplo. Nos dois casos, haveria impossibilidade ou grande 
dificuldade de se expressar, de transmitir suas vivências de um ponto de vista singular, para compartilhá-las com um outro. As interações intersubjetivas falham em maior ou menor grau. Entretanto, como lembra Soler (2010), "o fato de não falar não quer dizer que não sofra as incidências da fala sobre seu corpo" (p. 11).

O fato clínico que pretendemos discutir apresenta um aspecto que destoa do que geralmente é uma marca desta clínica: a exclusão transferencial do analista. Por ser refratária à relação com o agente do Outro, ao não se abrir para a relação pulsional que a introduziria no campo da libido, ao não se deixar investir pelo representante do Outro (ou ao não ser investida por este) ${ }^{2}$ e, consequentemente, não se deixar tomar em um primeiro momento como objeto que suscitaria o gozo do outro, a criança autista fica fora da dialética da demanda e do desejo. Sendo essa dialética encarregada de situar o gozo corporal do vivente em um gozo fora do corpo, investido em objetos que se trocam/compartilham com o agente do Outro no circuito pulsional, a criança não surge como ser libidinal. Permanece presa a um gozo estranho e ao corpo real. Ao mesmo tempo, em decorrência disso, sua relação com o campo da linguagem não se efetiva, no sentido de ela poder se representar pelos significantes. Ocorre uma colagem ao signo, uma exclusão do Outro, ou uma relação que pode ser direta com o Outro, tesouro dos significantes, não mediada por um agente que encarnaria essa função.

\section{O fato clínico}

Passemos à descrição do fato clínico, que já foi motivo de inspiração para um trabalho anterior, a partir de outro ponto que então nos fez questão na época:

Denis tem 10 anos, está em análise desde os 4 anos, após ter feito um trabalho analítico anterior de dois anos de duração. Ele iniciou seu trabalho de análise em sessões conjuntas com sua mãe, e depois passou a ter sessões individuais, quando passou-se a ter encontros mensais com a mãe (ou os pais), que depois ocorreram numa frequência bimensal aproximada. Ele frequenta uma escola normal, cursa a $4^{\text {a }}$ série do ensino fundamental, contando desde o início de sua escolarização com o auxílio de uma acompanhante terapêutica. Este trabalho escolar foi surpreendente, pois Denis não fala praticamente nada, pronuncia muitos sons ininteligíveis, dizendo algumas vezes algumas 
palavras, de modo assistemático, como "caiu", “amo" (para vamos), "papa”. Mesmo assim, ele está seguindo sua turma (com atividades diferenciadas) desde o pré e está alfabetizado para a escrita e talvez até para a leitura (uma hipótese ainda não confirmada). Numa sessão, Denis desenhava personagens Disney: Pateta, Pato Donald, Mickey... Escrevi numa folha: "AMIGOS", ao que ele respondeu escrevendo as seguintes letras: "MUES", que inicialmente nada significam. Em seguida, finalmente entendi, mudando a ordem das letras, que ele tentara escrever o pronome "MEUS" e lhe disse: "Ah! Você está me contando que o Donald, o Pateta e o Mickey são os SEUS amigos!". Ele então me olhou surpreso e demonstrou um grande contentamento, uma jubilação mesmo: pela primeira vez ele tinha se feito entender por meio de uma palavra, escrita intencionalmente por ele, mesmo que na forma de um lapso, porque em anagrama, ou até por isso mesmo, não era uma cópia, era uma tentativa pessoal de escrever, uma enunciação. Algo novo se produziu naquele momento: acabávamos de viver uma experiência de comunicação através das palavras. Aí se tornou evidente, de modo paradigmático, o sofrimento por ele vivido tantos anos por não conseguir se fazer entender pelos outros por esta via dupla, já que ele acostumou-se a fazer suas demandas com gestos e já que manifestara amplamente compreender o que lhe era falado. O que ele comunicava aí? Que queria ter amigos? Que tinha feito as amizades que estavam ao seu alcance: com os personagens de desenhos animados. Eles lhe falavam alguma coisa, eles viviam coisas que diziam o que precisava saber?

Comunicava também a sua extrema solidão, ao pé da letra, por se situar num lugar no qual não há pares. (Bernardino, 2006).

Como sustentar teoricamente esse movimento permitido pelo acesso à escrita formal e pela transferência? Como pensar a relação entre a aprendizagem das letras na alfabetização e a letra enquanto inscrição primária na montagem identificatória do sujeito? Dois campos heterônomos, mas interligados pela questão do significante: a escrita enquanto construção cultural de um povo e a escrita enquanto inscrição que funda o Inconsciente. Temos então duas vertentes para pensar a questão:

1. A aprendizagem da escrita, aspecto instrumental, marco de um determinado momento do desenvolvimento infantil;

2. O processo de constituição subjetiva, aspecto estrutural, fundador do sujeito.

Duas vertentes que, embora de campos bem diferentes, entrelaçaram-se nesta situação clínica.

\section{A aprendizagem da escrita e sua relação com a constituição subjetiva}

No que se refere à criança com desenvolvimento dito padrão, quando ela entra no período escolar e começa o processo de alfabetização, trata-se, para 
ela, de ser introduzida em uma nova relação com a linguagem e com a língua. É uma nova entrada no campo do Outro, tesouro dos significantes, desta vez sem a intermediação de um agente familiar, mas ainda assim com a figura do professor como intermediário, um representante do meio social. Vale ressaltar que a transmissão da linguagem nesse momento da escolarização formal não mais se refere ao banho dos significantes familiares, marcado pelo determinismo simbólico da linhagem familiar. Desta vez, trata-se de apreender a estrutura desse campo, de conhecer sua ordenação. Se por um lado trata-se de um campo totalmente exterior, já que não depende da criança para existir, está dado, com suas regras, seu funcionamento, por outro lado trata-se de um campo já instalado na criança, através do processo de constituição subjetiva: a estrutura da linguagem já está instalada nela, de modo inconsciente. Para a criança, há um reconhecimento, aos poucos, da língua falada na língua escrita e vice-versa, o que lhe propicia um ordenamento e uma ainda maior apropriação dessa linguagem que na sua pré-história se apropriou (Bernardino, 2006).

E nos casos de autismo, como isso se dá?

Sabemos que há alterações profundas na relação da criança com o gozo, a pulsão, o significante e a letra. Não há acesso da criança ao gozo do Outro. Rosine e Robert Lefort (2003) chegam a se referir a uma "relação com o Outro limpa de gozo" (p. 181). Esse acesso ao gozo do Outro, responsável pela articulação corpo/ linguagem, ocorre com a montagem do circuito pulsional completo, em que o bebê se oferece como objeto para proporcionar prazer ao agente do Outro com o usufruto de uma parte de seu corpo. Lacan já se referia, no seminário 9 (1995), a uma "relação do mundo do significante com o que chamamos de pulsão sexual, privilégio, prevalência da função erótica do corpo na constituição do sujeito" (p. 156, tradução nossa). Esse interesse em fisgar o gozo do Outro e a ele se alienar funda os alicerces do sujeito (Laznik, 1994). Ocorre uma alienação real das partes do corpo entregues ao Outro, como objetos de gozo, montando circuitos pulsionais que fundam zonas erógenas. Entrelaça-se a essa alienação real a alienação imaginária do estágio do espelho (responsável pela instância identificatória eu-ideal) e a alienação simbólica ao traço unário (responsável pela instância identificatória Ideal do eu). Mais tarde, com o processo edípico vindo significar os aspectos narcísicos e pulsionais em torno do falo, há o acesso à significação fálica, é possível o gozo do sentido, o gozo fálico.

Nos casos que se direcionam para o autismo, há um curto-circuito pulsional e a criança não chega ao terceiro tempo da pulsão, não entrando no campo do desejo e não se fundando como sujeito, no sentido lacaniano do termo (Laznik, 2004). 
O que ocorreria então, no caso da alfabetização de crianças cujo processo de constituição subjetiva falhou tão radicalmente? Crianças fora do discurso, sem acesso a uma fala própria, mas que têm acesso à escrita?

Talvez pudéssemos afirmar que, ao ingressar no sistema escrito do código, a criança tem a possibilidade de acessar a organização fálica contida na estrutura da linguagem, embora continue à margem de uma significação fálica própria de sua linhagem familiar, transmitida via complexo de Édipo, que lhe abriria uma possibilidade de dar sentido ao que a cerca, de modo a participar do laço social.

De todo modo, essa experiência que relatamos, bem como aquela expressa nos livros autobiográficos de autistas, evidencia a existência de linguagem, mesmo perante a ausência de fala, anterior ao aparecimento da fala: "Eles não sabiam que, em minha cabeça, eu já falava há muito tempo" (Nothomb, 2003, p. 36). É o que observamos também nos casos dos bebês em geral. Como afirma Milner (2000), para Lacan "o silêncio não existe; pode se dizer inconsciente, pode se dizer estrutura, pode se dizer linguagem" (p. 23).

A situação clínica aqui relatada permite propor a hipótese de que a experiência de aprendizagem da escrita pode ser uma nova oportunidade de estabelecer um encontro com o campo simbólico, com o Outro, um encontro propiciado através de uma figura de mediação estranha à família (o professor, o acompanhante terapêutico), ou mesmo um encontro direto, como muitas vezes ocorre com a criança que aprende sozinha a escrever, fato relatado em muitos desses casos de autismo com altas habilidades. Essa nova oportunidade pode se tornar um ato inaugural para essas crianças, na sua relação com o campo simbólico, de abertura para a função do Outro e de possibilidade de entrada na linguagem e no discurso. É o que se discute muito no âmbito da chamada educação terapêutica - os benefícios da escolarização e da aprendizagem formal para pôr em movimento um processo de constituição subjetiva que até então não se instaurou (Kupfer, 2000).

Para Bernard Nominé (conferência proferida em Narbonne, 25 de maio de 2010), "a posição da relação com a língua é essencial na posição autística". Ele observa que a criança com autismo "permanece refém do significante", num tipo de "gozo automático do significante". Para ele, há uma diferença radical entre essa "fascinação pelo real do significante" que ocorre no autismo e o "gozo do blábláblá que nos atinge a todos". Entretanto, ao se referir aos 
escritos de pessoas com autismo com altas habilidades (por exemplo, Daniel Tammet) ${ }^{3}$, ele reconhece que há ali um sujeito "animado por um desejo de nos transmitir sua experiência"!

Muito próximo dessa ideia está outro aspecto relevante do fato clínico: a percepção de que a criança com autismo em atendimento, geralmente caracterizada pelo retraimento, ao viver uma experiência em que sua escrita resulta em uma implicação com o outro que lhe permite expressar-se, reage de um modo surpreendente: ela demonstra através de suas reações um grande regozijo, ao perceber que o outro entendeu o que ela comunicou. A vivência transferencial é impactante, justamente porque ali onde não havia reciprocidade, ali onde não havia encontro, de repente algo novo se estabelece e é possível compartilhar algo, como descrevemos acima.

Será que poderíamos nomear esse gozo que toma conta da cena terapêutica de gozo fálico, segundo Lacan, já que se deve à palavra, ao sentido produzido? Afinal, mesmo nesta clínica difícil há esses momentos em que se produz, na transferência, conexão e compartilhamento da experiência.

O que propomos como hipótese é que o acesso à escrita permitiria a algumas crianças autistas certo acesso direto ao gozo fálico, gozo do sentido, embora não mediado pela significação fálica. Encontramos apoio teórico para esta hipótese em algumas ideias desenvolvidas por René Lew (2004) e M. C. Laznik (2010). Esses autores 
afirmam a existência muito precoce do acesso ao gozo fálico para a criança autista. De seus textos, entendemos que seria um gozo em uma total disjunção com o gozo do Outro, que se manifestaria por uma possibilidade de se situar em uma posição narcísica pura, ou seja, sem a reciprocidade própria ao narcisismo via estádio do espelho, que passa pelo olhar e pela significação do Outro. Um narcisismo disjunto da questão erógena pulsional. Essa posição narcísica centrada no próprio "eu” lembra a observação de Freud (1914/2004) ao se referir às "psiconeuroses narcísicas", as parafrenias e a paranoia, em que haveria esse narcisismo indiferenciado. Freud (1914/2004) assinala:

No princípio, as energias coexistem no estado do narcisismo e [que] são indiscerníveis para uma análise mais superficial. Somente quando passa a ocorrer um investimento nos objetos é que se torna possível distinguir uma energia sexual, a libido, de uma energia das pulsões do Eu. (p. 99)

Encontraríamos então apenas as pulsões do Eu, sem a sexualidade, sem o objeto, sem a consideração do outro.

Talvez pudéssemos pensar, em continuidade com as ideias de Lew (2004) e Laznik (2010), em um resgate desse registro fálico/ narcísico disjunto do gozo do Outro quando da entrada no processo de alfabetização, que permitiria um encontro desse primeiro gozo fálico do narcisismo corporal puro com o gozo fálico do sentido, imaginário, contido no uso do código de cada povo.

Lembremos que o Simbólico também é um corpo, seus elementos são coordenados por um sistema de relações. A aprendizagem da escrita permite um novo acesso para a criança a esse corpo organizado da língua. Ao ingressar no sistema escrito do código, a criança tem a possibilidade de acessar a organização fálica contida na estrutura da linguagem.

À primeira vista, observamos que a criança passa a dispor de um banco de dados - palavras escritas - que lhe permitem dispor de traços, marcas, que ela toma de empréstimo desse sistema, desse corpo organizado da língua escrita. Ao invés de ser habitada pela linguagem, ela a adquire cognitivamente. Mas pensamos que a forma como ela se relaciona com esse campo é fundamental, pois nem sempre ela fica de fora do discurso. Ela pode, por exemplo, descobrir que ao escrever ela pode se dizerer, expressar-se, e demonstrar sua afetação pela reação do outro, como relatamos neste fato clínico. O que poderia levar a supor a existência de uma demanda que até então estaria ali, mas latente, insuspeita. 
Nominé (conferência proferida em Narbonne, 25 de maio de 2010), ao se referir à "aposta mínima a fazer diante de uma criança autista" afirma que "há um sujeito ali dentro, e ele tem tudo a nos ensinar, se queremos entrar em comunicação com ele".

\section{A primazia da escrita para Lacan}

Dito isso passemos para o ponto de vista da escrita primordial, fundadora do Inconsciente, para examinar a afirmação de Lacan sobre a primariedade da escrita. Como aponta Milner (2000, p. 24), o que para Lacan em um primeiro momento era resumido em um "isso fala", em que a linguística se revelava decisiva, evolui no decorrer de seu ensino para um "está escrito", em que ideogramas e hieróglifos, muito mais do que mostrar, dizem algo. Assim, o pensamento lacaniano evolui de um inconsciente estruturado como uma linguagem para um inconsciente estruturado como uma escrita. Lacan dá destaque ao objeto, que não é significante, mas que pertence ao inconsciente, como aponta Leite (2001, p. 37). O objeto causa do desejo, "este aspecto do inconsciente, fora do significante, redefine a estrutura" (Leite, 2001, p. 38). Mas esse objeto não é simbólico, ele é real. Lacan (2003) então concebe o Simbólico organizado por um Real: "a estrutura é o real que vem à luz na linguagem” (p. 477), em que a letra seria a face real do objeto, já que ele se escreve no corpo, como assinala Cacciali (2010). 
A partir daí o próximo passo de Lacan foi articular linguagem e gozo ao propor o conceito de "alíngua", uma língua inesquecível, mas inacessível, o Isso, em que se articulam gozo e significante, corpo e linguagem. O inconsciente é concebido como um escrito, na cadeia literal contínua (Cacciali, 2010). Nesse contexto, "alíngua" é "amálgama de gozo com significante" em que "o sujeito se constituirá como 'parlêtre', marcado pelo significante, condicionado pela letra" (Leite, 2001, p. 40).

Milner (2006) propõe: "alíngua é o real de um encontro contingente entre R, S e I" (p. 33) que sela a articulação entre o real de alíngua, o imaginário da linguagem (o signo) e o simbólico da língua sendo alíngua, em última instância, "a encarnação do simbólico" (p. 34). Vale destacar, para continuar nossa reflexão, que há um caminho a percorrer entre o real de alíngua e sua efetivação simbólica na língua (Milner, 2006, p. 38, itálico nosso).

Assim, poderíamos pensar que no autismo não há essa efetivação de alíngua, não há o enodamento RSI necessário para organizar o encontro corpo/linguagem. A falha no circuito pulsional, o não encontro com as inscrições do desejo do outro no corpo próprio não permitiram a encarnação do simbólico em Alíngua. A escrita primeira falhou. Há disjunção entre corpo e linguagem, não há enodamento entre o real corporal, o imaginário da linguagem (do signo), que permite as significações e o campo simbólico da língua.

Seria possível então afirmar que o acesso à escrita pela via da alfabetização permitiria à criança com autismo um acesso ao campo simbólico da língua sem encarnação; entraria na língua sem passar por Alíngua. Haveria linguagem enquanto acesso aos significados próprios do código, aos signos, inerentes à estrutura da língua, o que propiciaria seu acesso às significações gerais, embora não à polissemia do significante.

É o que observamos nas pessoas com autismo com altas habilidades que narram sua experiência em livros ${ }^{4}$. Nominé (conferência proferida em Narbonne, 25 de maio, 2010 “Aprendre de l'autiste", tradução nossa) observa: "Eles têm um uso do significante totalmente correto. Estão no universo da linguagem, não estão excluídos daí, mas o que não funciona bem se situa no nível da fala". Ele demonstra que a falha se situa na representação do mundo, que "é assunto de sujeito", depende da posição do sujeito.

Ao debater em seu texto com Maleval (2009) - para quem no autismo se está num universo de signos -, Nominé (conferência 
proferida em Narbonne, 25 de maio, 2010, “Aprendre de l'autiste”, tradução nossa) discorda, prefere falar do real do significante e da relação espontânea entre significantes que se opõem. Para ele, as pessoas com autismo estariam nesse nível significante, "o que não basta para construir uma representação de mundo". Para aparelhar seu gozo aos significantes do Outro, é preciso renunciar a uma parte de gozo em troca do reconhecimento e do amor do Outro. No autismo não há essa renúncia, o que impossibilita a representação do mundo ao não dispor dos significantes do Outro.

Entretanto, ao se referir ao livro de Daniel Tammet ${ }^{3}$, Nominé (conferência proferida em Narbonne, 25 de maio, 2010, “Aprendre de l'autiste”, tradução nossa) se pergunta "como ele passou deste estado [autístico] àquele no qual evolui se endereçando aos outros com a vontade de lhes transmitir algo?". Ele propõe como resposta o encontro com outra língua e a necessidade de passar pela tradução e pelo manejo dessa outra língua, a partir de uma experiência que vivenciou de afastamento de sua família.

Mas poderíamos, ainda assim, questionar o estatuto do significante no autismo, partindo da definição de significante como o que representa o sujeito para outro significante, já que justamente o que não está presente na maioria dos casos é a possibilidade de representação. Haveria sujeito, conforme Lacan o define, este que só aparece entre significantes, no autismo?

Já para René Lew (conferência proferida nas Jornadas Préaut/ ALI, 17 outubro, 2004, "Fonction de la jouissance dans l'autisme", tradução nossa), "o sujeito autista está compactado em seu narcisismo, identificado com o Um”, referindo-se a um Outro não distinguível, mantido pela essência do significante, mas este Um não põe em jogo a sexualidade, nem a fortiori o Outro. Para Lew, a pessoa com autismo "mantém uma opção de sujeito, mas nada mais: estritamente narcísica, e sem desenvolvimento altruísta" (conferência proferida nas Jornadas Préaut) ALI, 17 outubro, 2004, "Fonction de la jouissance dans l'autisme", tradução nossa ). Haveria então um gozo fálico, o corpo inteiro tendo valor de falo, embora este gozo fálico enquanto tal não fosse dialetizável, pois não se contrapõe antinomicamente ao gozo do Outro. Seria um gozo fálico não ancorado na inscrição do significante do Nome-do-Pai, aquém do Édipo, aquém da metáfora paterna.

Retomando então nossa hipótese após essas considerações, gostaríamos de propor uma diferenciação.

Em muitos casos de autismo há acesso à escrita, mesmo não havendo letra enquanto escrita inconsciente. O que a criança encontra são as letras do alfabeto, do código - exteriores ao corpo e ordenadas pela estrutura simbólica, também externa, não introjetada. Letra, enquanto marca libidinal do Outro que delineia uma geografia erótica, não há, já que alíngua não fura a consistência do corpo, sua efetivação fracassa. É possível haver uma relação com o significante, mas 
disjunto de alíngua e da pulsão, torna-se ele próprio signo, objeto de gozo. Nesse sentido, o significante na escrita pode configurar um usufruto da linguagem, mas destacado do laço social, uma fala que se basta a si mesma, que não é mensagem, não investe no parceiro, como assinala Soler (2010). Por exemplo, muitas crianças com autismo reproduzem por escrito palavras de outdoors, de propagandas na TV, mesmo que não saibam ler o que escreveram ou que pareçam não entender o que essas palavras querem dizer. Nesse caso, sofrem uma intrusão desses significantes, são muito mais capturadas por esses significantes do que fazem uso deles.

Entretanto, o fato clínico que discutimos se diferencia disso. O que percebemos são escrituras onde ocorrem lapsos, demonstrando outra apreensão da escrita, diferente da colagem ao signo e, principalmente, evidenciando o que nós psicanalistas costumamos identificar como um significante, uma formação do inconsciente, na medida em que essa falha remete a uma produção de sujeito, bem diferente da colagem. O exemplo de Denis permite pensar que há um sujeito aí sim, que entre os significantes "mues" e "meus" algo remete/representa um sujeito, sua solidão e seu universo particular. Mas há que reconhecê-lo!

Podemos ainda pensar no que os professores alfabetizadores chamam de erro das crianças que começam a escrever, que evidencia um trabalho de ensaio, de apropriação em relação à escrita.

Além disso, outro diferencial deste fato clínico é que, ao afetar o outro, tem lugar o júbilo, ocorre a vivência transferencial do "falar" através do escrito e ser ouvido, levando inclusive a um início às vezes bem tardio da linguagem oral (como foi o caso de Denis). É verdade que essa escritura é "lançada aos bastidores" - como situa Erik Porge (1986, p. 11), a partir de uma expressão de Lacan em O seminário, livro 11 (1985a) -, e não a um destinatário específico.

O que também se evidencia no fato clínico que ora discutimos é que na análise a criança encontra um destinatário, alguém que se apresenta - na transferência - como o receptáculo de sua produção, e que toma sua produção como um dizer. Esse fato, quando dá margem para que algum dizer possa remeter a um lugar de enunciação, quando esse dizer irrompe no meio do dito e dá abertura para a troca, inaugura algo para ela. Trata-se de encontrar um interlocutor e experimentar a transferência. É possível compartilhar - "falar" e "ser ouvida". Se a criança é fisgada então pelos afetos do agente do Outro - a surpresa, a alegria, a tristeza, a braveza - é possível para 
ela atrelar esses afetos a essas experiências, não mais "limpas de gozo", mas carregadas do afeto provocado no outro, ou seja, com significação.

Poderíamos então dizer que a escrita aí permite des-colar do Simbólico para servir-se dele, introduz a possibilidade de aproximação com o "ser libidinal", por esse acesso à escrita que diz algo e que leva à afetação do outro e à própria afetação da criança, permitindo fundar um laço social. Utilizar um código para se dizer é estabelecer laço social, é entrar no discurso.

A escrita, então, nesses casos, poderia permitir a passagem da relação colada ao significante ou do gozo corporal para outro tipo de encontro com a linguagem, com essa ordenação que é o sistema da escrita. Se Lacan propõe no seminário 18 (2009) que o escrito não é a linguagem, mas é o que permite interrogar a linguagem (p. 60), talvez a criança com autismo com seu escrito nos questione, na transferência, sobre a relação que estabelecemos com a linguagem, para d'Isso saber alguma coisa.

Alíngua como "depósito que supõe o enlace do sentido e do gozo” (Soler, 2010, p. 17) não se efetivou. Não houve captura da criança como objeto de gozo do outro, o gozo do outro não foi fisgado, o corpo não se pulsionalizou. Mas o acesso à língua pela via escrita pode fornecer à criança um tipo de "aparelho de gozo" como refere Lacan (1985a), mas desta vez linguístico, ordenado, com limitação do gozo corporal e com um sentido, a serviço da fala e do laço social.

Para isso, é necessária uma aproximação entre a letra aprendida para se alfabetizar e a letra enquanto marca de uma implicação erógena com um outro, o que pressupõe uma relação com um outro e seu desejo - condições ligadas ao papel do analista.

\section{Considerações finais}

A criança com autismo faltou ao encontro pleno com Alíngua, não pôde comparecer a ele. Mas ela pode encontrar-se com a língua - enquanto código formal - no acesso à escrita, e ter uma aproximação com o campo do afeto compartilhado. Isso pode atuar como um convite para que ela se afete e aceite sair de seu autismo. Como diz Lacan (1985b): "Alíngua nos afeta primeiro por tudo que

516 Estilos clin., São Paulo, v. 20, n. 3, set./dez. 2015, 504-519. 
ela comporta como efeitos que são afetos" (p. 190).

Seguindo esse desenvolvimento, para a direção de tratamento da criança autista pode-se pensar na importância do processo de alfabetização que permite o exercício de uma linguagem com significação para a transmissão de uma experiência, de uma vivência pessoal, que inclui o corpo e inclui o outro como interlocutor. Ressalta-se então a relevância da inclusão escolar, que favorece a aprendizagem formal do código. E ressalta-se a importância do trabalho analítico e da relação transferencial para que esse código possa ser transformado em palavras que remetam ao corpo, às vivências, aos afetos, e possam encontrar ressonâncias no outro. Seria como uma suplência do processo de constituição subjetiva ancorado no circuito pulsional do bebê, que não foi vivido pela criança que se torna autista, suplência ao mesmo tempo marcada por essa limitação. $\mathrm{Na}$ cena terapêutica, analista e analisante podem ter um encontro que enlace $R$, $\mathrm{S}$ e I, e daí podem surgir significantes a compartilhar.

THE IMPORTANCE OF WRITING IN THE AUTISM CLINIC

\footnotetext{
Abstract

The following up of children with autism can indicate a direct relation with the symbolic field by the cognitive pathway, sometimes very developed, other times idiosyncratic. Therefore, we can find a situation in which, differently of what is seen in children with the so called standard development, it is by the writing and by literacy that the child with autism begins to
}

communicate with other people. According to Lacan, the writing goes first in relation to speech, and we intend to identify through concepts like letter, signifier and enjoyment a possible understanding of this enigmatic universe of the autism to bring contributions to the direction of treatment of these children.

Index terms: autism; writing; drive; letter; signifier; enjoyment.

\section{LA IMPORTANCIA DE LA ESCRITURA EN LA CLÍNICA DEL AUTISMO}

\section{REsumen}

El acompañamiento de niños con autismo permite apuntar una relación directa con el campo simbólico a través de la dimensión cognitiva, a veces desarrollada otras idiosincrática. En este sentido y contrariamente a lo que sucede con niños de desarrollo presuntamente "normal" se puede encontrar una situación en que es gracias a la escritura y a la alfabetización que un niño, considerado autista, puede tener posibilidades de comunicación. Si para Lacan la escritura es primera con relación al habla, pretendemos encontrar en conceptos, tales como letra, significante y goce, un camino posible de comprensión de este universo autista tan enigmático, así como subsidios para la dirección clínica de su tratamiento.

Palabras clave: autismo; escritura; pulsión; letra; significante; goce.

\section{REFERÊNCIAS}

Bernardino, L. M. F. (2006). De que pathos se trata no autismo. In Anais do II Congresso Internacional de Psicopatologia Fundamental e VIII Congresso Brasileiro de Psicopatologia Fundamental. Belém, PA/Brasil. Recuperado de http://www. psicopatologiafundamental.org/uploads/ files/ii_congresso_internacional/mesas_redondas/ii_con._de_que_pathos_se_trata_no_autismo.pdf

Cacciali, J-L. (2010). La voix et la lettre. La Revue Lacanienne, 2(7), 111-115. doi: 10.3917/lrl.102.0111 
Freud, S. (2004). À guisa de introdução ao narcisismo. In S. Freud, Escritos sobre a psicologia do inconsciente. (L. A. Hanns, trad., Vol. 1). Rio de Janeiro, RJ: Imago. (Trabalho original publicado em 1914)

Kupfer, M. C. (2000). Educação para o futuro: psicanálise e educação. São Paulo, SP: Escuta.

Lacan, J. (1985a). O seminário, livro 11: os quatro conceitos fundamentais da psicanálise, 1964. Rio de Janeiro, RJ: Jorge Zahar.

Lacan, J. (1985b). O seminário, livro 20: mais... ainda, 1972-1973. Rio de Janeiro, RJ: Zahar.

Lacan, J. (1995). L'identification. Séminaire 1961-1962. Paris, France: Association Freudienne Internationale. (Edição para circulação interna)

Lacan, J. (2003). O aturdito. In J. Lacan, Outros escritos (pp. 448-500). Rio de Janeiro, RJ: Jorge Zahar. (Trabalho original publicado em 1973)

Lacan, J. (2009). O seminário, livro 18: de um discurso que não fosse semblante, 1971. Rio de Janeiro, RJ: Jorge Zahar.

Laznik, M-C. (1994). Por uma teoria lacaniana das pulsóes. In C. Dorgeuille (Org.), Dicionário de psicanálise: Freud \& Lacan (Vol. 1, pp. 209-224). Salvador, BA: Ágalma.

Laznik, M-C. (2004). A voz da sereia: o autismo e os impasses na constituição do sujeito. Salvador, BA: Ágalma.

Laznik, M-C. (2010). Godente ma non troppo. Psicologia Argumento, 28(61), 135-145.

Lefort, R., \& Lefort, R. (2003). La distinction de l'autisme. Paris, France: Seuil.

Leite, M. P. S. (2001). O inconsciente está estruturado como uma linguagem. In O. Cesarotto, Idéias de Lacan (pp. 31-42). São Paulo, SP: Iluminuras.

Maleval, J-C. (2009). L'autiste et sa voix. Paris, France: Seuil.

Milner, J-C. (2000). De la linguistique à la linguisterie. In J. Aubert, F. Cheng, J-C. Milner, G. Wajcman, \& F. Regnault (Dir.) Lacan, l'écrit, l'image (pp. 7-25). Paris, France: Flammarion.

Milner, J-C. (2006). Os nomes indistintos. Rio de Janeiro, RJ: Companhia de Freud.

Nothomb, A. (2003). Metafisica dos tubos. Rio de Janeiro, RJ: Record.

Porge, E. (1986). Le transfert à la cantonnade. Littoral, L'enfant et la psychanalyse, 18, 5-16.

Soler, C. (2010). O “corpo falante”. In D. Fingermann (Org.), Caderno de Stylus 1: o "corpo falante" (pp. 09-29). Rio de Janeiro, RJ: IF-EPFCL.

Tammet, D. (2007). Nascido em um dia azul. Rio de Janeiro, RJ: Intrínseca

Vorcaro, A., \& Lucero, A. (2010). Entre real, simbólico e imaginário: leituras do autismo. Psicologia Argumento, 28(61), 147-157.

Zuliani, E. (2008). Autisme, automatisme mental et traitement de l'être. In J. L. Bonnat (Dir.), Autisme et psychose: machine autistique et délire machinique, clinique différentielle des psychoses (pp. 113-122). Rennes, France: Presses Universitaires de Rennes.

\section{NOTAS}

1. Uma versão reduzida deste trabalho foi apresentada no Congresso Internacional sobre Autismo: Prevenção, intervenção e pesquisa, realizado em 2011 em Curitiba. Outra versão foi apresentada no Café Cartel em 2012, no Fórum do Campo Lacaniano em São Paulo. Agradecemos a interlocução dos colegas Angela Vorcaro, Christian Dunker, Dominique Fingermann e Ricardo Goldenberg, parceiros de cartel sobre o seminário 18 de Lacan, que inspiraram esta escrita!

2. Não entraremos na polêmica quanto à causalidade do autismo, na medida em que entendemos o autismo como consequência da não montagem do laço bebê/Outro primordial, independentemente do pólo de que partiu a dificuldade inicial. 
3. Referência ao livro de Daniel Tammet (2007).

4. Exemplos de livros escritos por pessoas com autismo: Sellin, B. (1999). Une ame prisionnière. Paris: Robert Laffont; Williams, D. (1992). Si on me touche, je n'existe plus. Paris: Robert Laffont; Grandin, T. (1994). Ma vie d'autiste. Paris: Odile Jacob; Harbaudière, D. (1991). Cati ou les Sentiers de la vie. Paris: Belfond; Tammet, D. (2007). Nascido em um dia azul. Rio de Janeiro: Intrínseca; Nothomb, A. (2003). Metafísica dos tubos. RJ: Record; Higashida, N. (2014). O que me faz pular. RJ: Intrínseca.

ledber@terra.com.br

Rua Mateus Grou, 57/42

05415-050 - São Paulo - SP - Brasil. 